\title{
Sob as demandas do tempo: o horizonte político no projeto literário amadiano
}

\author{
Júlio César da Luz* \\ Alessandra S. Brandão**
}

\section{Resumo}

No contexto de acirramento ideológico da década de 1930 no Brasil, a publicação de Cacau, em 1933, de Jorge Amado, levantou a discussão, entre críticos e escritores, acerca do denominado "romance proletário", até então pouco mencionado no país. A despeito de todo o acalorado debate que se seguiu, persistiu, no entanto, um sentido um tanto impreciso, o novo gênero entendido segundo diferentes e, muitas vezes, conflitantes noções. Este trabalho recoloca essa questão, pensando-a a partir da perspectiva com que Roberto Schwarz considera a experiência intelectual brasileira, assinalada pela importação e o deslocamento de ideias europeias, cuja impropriedade exprime-se nas contradições com o contexto dissonante de sua assimilação. Partindo do debate desencadeado em torno da publicação de Cacau, busca-se relacioná-lo ao projeto ideológico que norteou a produção amadiana no início de sua carreira literária, a fim de entender o romance nos deslocamentos operados pelo ficcionista para que pudesse coaduná-lo às condições contextuais sob as quais escreveu.

\section{Palavras-chave}

Romance proletário. Jorge Amado. Cacau.

\section{Introdução}

Na década de 1930, o campo intelectual brasileiro vivenciou um processo de radicalização ideológica decorrente de um contexto de intensas transformações no país e no mundo. Os conflitos do campo político atingiam literatos e críticos, envolvendo-os

\footnotetext{
* Especialista em História da Arte (Unisul) e mestrando do Programa de Pós-Graduação em Ciências da Linguagem (Unisul)

** Doutora pela Universidade Federal de Santa Catarina e professora do Programa de PósGraduação em Ciências da Linguagem (Unisul).
} 
nas discussões de um contexto de acirramento das tensões ideológicas, quando se Ihes evidenciava, cada vez mais, a consciência da luta de classes. A perspectiva de crítica social vincou profundo especialmente a produção romanesca, numa forte vaga de radicalismo que fez despertar escritores de ação, comprometidos com a reflexão, a sondagem e a denúncia dos problemas sócio-político-econômicos do país. Os romancistas de $30^{1}$, como se cristalizou pela crítica denominá-los, não obstante a diversidade de sua produção, foram insuflados - nem todos, é certo - por esse projeto ideológico comum.

Sob o clima de fermentação política desse contexto de transformações, num decênio que se abria com a revolução liberal que derrubara a República oligárquica, mais que denunciar, no entanto, parte da intelectualidade brasileira desejava, na verdade, interferir no processo histórico, motivada pelos ideais utópicos de mudança social. No campo da literatura, essa visada se expressou no surgimento e nos debates em torno do chamado "romance proletário", popularizado no país principalmente com a publicação, em 1933, de Cacau, de Jorge Amado. Literatura imbricada em projeto político, o romance proletário nasceu e se difundiu sob o influxo da atmosfera ideológica após o êxito da Revolução Soviética, mobilizando escritores militantes, alinhados com a esquerda, em diferentes países.

Entravam, então, no Brasil, inúmeras traduções de romancistas comunistas, entre os quais os soviéticos Ehrenburg, Fadeiev, Gladkov, Lebedinski, Vieressaief e Pliniak, os franceses Malraux e Barbusse e os estadunidenses Michael Gold e Upton Sinclair (DUARTE, 1996, p. 28). Partidários da Revolução Russa, sua literatura manifesta uma declarada intenção participante, tornando-a instrumento de "desalienação", de "formação de consciência". Porém, embora a literatura operária essa literatura que mergulha no universo dos trabalhadores, expondo-o sobretudo em suas formas de resistência na luta de classes - tenha vindo ao encontro, no Brasil, de um ambiente de recrudescimento ideológico, de polarização dos conflitos do campo político, com a ascensão da esquerda, também veio, por outro lado, de encontro a um contexto socioeconômico predominantemente rural, quando a classe operária, concentrada nas principais cidades industrializadas, ainda se formava. É significativo, nesse sentido, que Cacau, obra que pela primeira vez suscitou debate acalorado entre críticos e escritores acerca do romance proletário no país, seja na verdade um romance proletário sobre os trabalhadores rurais da zona cacaueira baiana. O próprio autor hesita, promovendo mesmo a discussão com a interrogação final da epígrafe com que abre o livro: "Será um romance proletário?" (AMADO, 2001, p. IX).

\footnotetext{
1 Denominação imprecisa, por demais elástica, muito abrangente ou, pelo contrário, bastante redutora, são "romancistas de 30", "sem que ninguém discorde", como Dacanal (2001) observa, José Américo de Almeida, Graciliano Ramos, Jorge Amado, Erico Verissimo, José Lins do Rego, Cyro Martins, Raquel de Queiroz, Ivan Pedro de Martins e Aureliano de Figueiredo Pinto. Contudo, ainda segundo o crítico, há inúmeros outros romancistas do período, a exemplo de Lúcio Cardoso, Cornélio Pena, Octávio de Faria, Dyonélio Machado, Cyro dos Anjos, Amando Fontes, João Alphonsus, Guilhermino Cesar, Adonias Filho e Jorge de Lima, os quais também escreveram na década de 1930, não obstante as diferenças que não permitem inseri-los ao lado dos primeiros nomes evocados. Ademais, a denominação torna-se tanto mais problemática quanto se levantam outras questões: e os que escreveram nas décadas seguintes? E as obras dos "romancistas de 30" posteriores a essa década? E quanto aos seus trabalhos que destoam das características gerais do chamado "romance de 30"?
} 
Será que o escritor brasileiro não importava - numa tradição que atravessa séculos de sua formação literária, durante os quais condenado como esteve aos condicionamentos de sua situação de país colonizado - um modelo estranho, dissonante de seu contexto? Ora, a experiência intelectual brasileira, segundo Schwarz, foi marcada pela importação de ideias europeias que, no entanto, aqui introduzidas, entravam em contradição com uma realidade sócio-econômico-cultural à qual não podiam corresponder. Porém, por outro lado, se não podiam ser descartadas, em virtude da condição secular de dependência econômica ao mercado europeu - que por longo tempo manteve o país em conexão "imprescindível" com a Europa - foram absorvidas e deslocadas, num processo que o singularizou, constituindo "uma espécie de chão histórico" que teve consequências para a vida cultural brasileira e, portanto, também para a produção literária e artística em geral (SCHWARZ, 1992, p. 12-15).

A "impropriedade" dessas ideias estrangeiras assimiladas no Brasil, "ideias fora do lugar", consoante as palavras de Schwarz, vincaram por séculos a experiência intelectual do escritor e do crítico brasileiros. Uma experiência, entretanto, complexa, condicionada, de acordo com Candido (1985), por uma "dialética do localismo e do cosmopolitismo". Se momentos houve, na história literária do Brasil, de "declarado conformismo", de "imitação consciente dos padrões europeus", outros houve de "afirmação premeditada e por vezes violenta do nacionalismo literário." Momentos fundamentais, nesse sentido, de particularismo literário, na dialética do local e do cosmopolita, teriam sido o Romantismo, no século XIX, e o Modernismo, no início do século XX. Contudo, se no Romantismo - embora fosse desejada uma independência cultural que acompanhasse a recente emancipação política - o intelectual brasileiro continuava quase que a "decalcar" ainda os padrões europeus, no Modernismo superava-se já a pura e simples assimilação das ideias europeias, simbolizada no gesto antropofágico (CANDIDO, 1985, p. 109-112).

Fase de amadurecimento e expansão do Modernismo, a década de 1930 não apenas consolidou o "projeto estético" da nova literatura (renovação da linguagem, libertação do academismo), mas também o aprofundou, desenvolvendo um "projeto ideológico" sobre o qual recaiu a ênfase de suas discussões: tornam-se, então, matéria central de debate "a função da literatura, o papel do escritor, as ligações da ideologia com a arte" (LAFETÁ, 2000, p. 28). É nesse contexto que se desenvolve, no Brasil, o chamado romance proletário; contexto em que a literatura se encontra envolta nas lutas do campo político, numa vaga de radicalização ideológica na esfera da arte no mundo que se segue à revolução socialista na Rússia. Essa literatura operária, que passa a constituir então o projeto literário de intelectuais militantes em vários países onde a esquerda se fortalece, era introduzida no Brasil, traduzida e discutida. Sob a atmosfera de transformações na arte e no campo do poder, de recrudescimento dos conflitos de classes e de engajamento político do intelectual brasileiro, essa literatura entraria sem dissonar, nesse sentido, com o contexto no Brasil de 1930, e não deixaria, é certo, de reverberar na produção de escritores do país. 


\section{0: a literatura sob um contexto de radicalização ideológica}

O processo crescente de bipolarização ideológica, no Brasil e no mundo, nas primeiras décadas do século $X X$, assinala o contexto para a compreensão do que se convencionou denominar "romance de 30". Com a Revolução Soviética, em 1917, e, em seguida, a reação nazi-fascista na Europa, os conflitos entre esquerda e direita se tornariam cada vez mais violentos. No Brasil, a exacerbação das tensões ideológicas se evidenciaria, sobretudo, a partir dos anos de 1930. Tendo sido fundado no Brasil em 1922, o Partido Comunista ascendia entre trabalhadores, estudantes e intelectuais, logo entrando em choque com a força reacionária da AIB, a Ação Integralista Brasileira, organizada em 1933, sob o influxo do ideário fascista. Com o acirramento do conflito, seria formada, em 1935, a ANL, a Aliança Nacional Libertadora, frente de esquerda sob orientação comunista, a qual culminaria numa frustrada tentativa de golpe de Estado. No campo da literatura, sob esse contexto de bipolarização ideológica, teria ocorrido, então, a mudança apontada por Lafetá, do "projeto estético" que teria norteado a produção da década de 1920, para o "projeto ideológico" de 1930. Segundo esse crítico, no contexto do decênio de 30, "A consciência da luta de classes, embora de forma confusa, penetra em todos os lugares - na literatura inclusive, e com uma profundidade que vai causar transformações importantes" (LAFETÁ, 2000, p. 28). Tais transformações se expressam no desenvolvimento do "romance de 30", uma literatura problematizadora, empenhada em esquadrinhar a realidade do país, denunciando suas estruturas socioeconômicas - principalmente aquelas arcaicas, de seu interior. Neste gênero, segundo Candido, "o mais característico do período e freqüentemente de tendência radical, é marcante a preponderância do problema sobre o personagem" (CANDIDO, 1985, p. 124). Deslocando o foco de interesse do personagem para o meio social, interessava menos mergulhar no intricado psicológico do indivíduo - centro das preocupações, segundo uma cisão ideológica assentada na época, de uma vertente mais devotada a um romance de orientação "intimista" - do que discutir o "problema": êxodo rural, banditismo social, coronelismo, condições de vida, de trabalho e organização da classe operária.

Ligando seu trabalho à reflexão dos problemas sociais do país, os escritores mobilizados pelo novo "projeto ideológico" assumiram um compromisso com uma "arte de denúncia", envolvidos pelas demandas de um tempo de radicalismo que thes impunha uma definição política; não Ihes era possível ficar "em cima do muro". Fosse à esquerda, ligada a uma postura engajada de crítica social, fosse à direita, representada numa tendência espiritualista mais conservadora, os críticos e os escritores brasileiros se encontravam, na década de 1930, completamente imersos no debate ideológico. Nesse contexto, segundo Bueno, acabavam vendo mais "a literatura pela ótica da luta política e fechavam os olhos para aquilo que não dizia respeito a ela" (BUENO, 2006, p. 172). A obra era comumente avaliada por fatores extrínsecos, reduzindo-se com frequência o trabalho do crítico em exaltar os autores com os quais 
se identificavam ideologicamente e em reprovar aqueles com os quais não se identificavam. O intelectual brasileiro se via enleado nos conflitos do campo político, enredado na situação de um ambiente crítico onde não eram pequenas "a confusão e as simplificações, levando os homens de letras, de acordo com sua orientação ideológica, a aceitar ou rejeitar de imediato um determinado livro" (BUENO, 2006, p. 168).

Foi nesse contexto que o romance proletário entrou na pauta das discussões de críticos e escritores, um tanto quanto envolvido pela "confusão" que marcava o campo intelectual do período. Pouco mencionado até então no Brasil, o romance proletário desencadearia discussão acalorada a partir de meados de 1933, quando da publicação quase simultânea de Cacau, de Jorge Amado, Serafim Ponte Grande, de Oswald de Andrade e Os Corumbas, de Amando Fontes (BUENO, 2006, p. 159-160). Tendo sido o romance que então suscitara maior debate, Cacau incitava, com a interrogação de sua nota de abertura ("Será um romance proletário?"), os literatos e a crítica a respondê-la.

Sujeito que figurava, com presença ascendente no transcurso da década de 1930 no campo cultural, o proletário constituía tema explorado sob diferentes perspectivas pela literatura. No processo de sua emergência, o proletariado passa a interessar enquanto tema à produção artística num contexto em que os escritores marcam posição nas lutas do campo do poder.

\begin{abstract}
À autonomização relativa do campo intelectual correspondeu o assentamento de uma conduta entre os produtores que se converteu em "regra" para eles: uma vinculação aberta, amplamente explicitada, com movimentos e organizações políticas. Embora se registrasse uma ofensiva da literatura no âmbito da cena política a partir do momento em que foi consolidada a condição do "proletariado", enquanto objeto de reflexão da produção literária, ocorreu também uma apropriação sua pelos demais produtores, que não necessariamente acataram os ditames de vinculação a organismos políticos. (ALMEIDA, 1979, p. 109).
\end{abstract}

Portanto, não obstante diferentes autores tenham se servido do tema à sua produção, a representação do proletário, nos múltiplos aspectos de suas condições de vida ou de trabalho, não classificava a obra, resumindo-se a aspecto temático, como romance proletário. "A aceitação do tema 'proletariado'", ainda consoante Almeida, não implicava "a aceitação do caráter de classe das normas literárias tal como sugerido pelas noções de romance proletário." (ALMEIDA, 1979, p. 110). Entendido sob noções diversas, num debate com o qual escritores e críticos brasileiros mal tinham contato, a expressão mais adquiria um sentido genérico do que uma definição precisa. Entre os poucos traços consensuais, o "caráter de classe das normas literárias" de que fala Almeida, manifesto em certos aspectos que caracterizam esse romance e que evidenciam, por outro lado, o posicionamento político do escritor.

No debate que se travou em jornais e revistas, investigado por Bueno num detido estudo sobre o romance de 30 , sobressai o interesse de intelectuais de esquerda, alinhamento político imbricado na literatura operária que surgira e se expandira no contexto revolucionário soviético. Para um intelectual comunista como Alberto Passos Guimarães, que se manifestara a propósito da questão levantada por Jorge Amado logo após a publicação de Cacau, o romance proletário deveria se 
constituir a partir de três elementos: "valorização da massa, rebeldia, descrição veraz da vida proletária." (BUENO, 2006, p. 164). O próprio romancista, por outro lado, além de reiterar os aspectos ressaltados por Alberto Passos, acresceria outros, de ordem ideológica, propondo que tal romance deveria "se despreocupar com a moral burguesa", e de ordem literária, estabelecendo, ao privilegiar o "coletivo" em detrimento do individual, uma ruptura com o enredo e o herói, categorias narrativas que definiriam o romance burguês (BUENO, 2006, p. 164-165). Intelectuais não alinhados à perspectiva ideológica de Jorge Amado e Alberto Passos também participaram do debate. Porém, não obstante toda a discussão que mobilizou diferentes críticos e escritores em torno do romance proletário, segundo Bueno persistiu uma definição pouco precisa, assentada, em síntese, sobre "três pilares espírito documental (especialmente voltado para a vida das camadas mais pobres), movimento de massa e sentimento de luta e revolta." (BUENO, 2006, p. 207).

No seu estudo do que se cristalizou considerar pela crítica a primeira fase do projeto literário de Jorge Amado, marcada por um viés ideológico sob o influxo da literatura operária e de sua militância comunista, Duarte menciona outros elementos caracterizadores do romance proletário, gênero em que se classificam algumas obras iniciais do romancista baiano:

\begin{abstract}
Ao colocar o homem que trabalha como protagonista ou narrador, tal romance se volta para o avesso das relações de exploração e subverte a noção idealizada existente desde os primórdios do gênero. Ao mesmo tempo em que denuncia o modo de exploração capitalista e a visão de mundo que o sustenta, o romance proletário contrapõe-se aos valores da literatura burguesa e às suas regras de operação. O oprimido ascende a herói e conta sua experiência como forma de extrair do fato narrado um saber transmissível a outrem. A dimensão utilitária se evidencia quando o texto expõe a vivência dos oprimidos, e ainda mais, quando parte para a pedagogia da insubmissão. A narrativa se volta para o real, abraça a tradição do romance como "instrumento de descoberta e interpretação", estabelecida desde os primórdios do gênero no Brasil, e destaca as relações sociais antagônicas, objetivando construir não uma literatura diletante, mas a obra empenhada no processo de transformação da sociedade. (DUARTE, 1996, p. 30).
\end{abstract}

Literatura para um momento de intensa fermentação política, o compromisso ideológico do romance proletário o imbrica nas tensões do campo do poder, enredando-o num projeto em que ao especificamente literário conjugam-se elementos extrínsecos. Daí a "dimensão utilitária", mencionada por Duarte, num romance cuja visada é a denúncia do capitalismo. Literatura a serviço dos interesses proletários, instrumento de "desalienação", construída, muitas vezes, sob os intentos pedagógicos do autor militante. Romance, enfim, entendido como "arma", imbuído de um fito utópico, "empenhado no processo de transformação" que culminaria com a superação do capitalismo, tal qual o exemplo soviético ensinara.

Contudo, embora presentes esses elementos em alguns dos trabalhos de Jorge Amado, o modelo não deixaria de assumir feições particulares, decorrentes das condições do contexto sócio histórico em que emergira no Brasil. As "condições específicas de uma dada formação social", segundo Almeida, demandaram uma "adequação do romance proletário", numa "tentativa de Amado e seus intérpretes de coadunarem normas universais de um gênero com uma situação histórica particular." (ALMEIDA, 1979, p. 116). 


\section{Um romance proletário dos homens do cacau}

Cacau, segundo romance de Jorge Amado, marca sua guinada à esquerda, dois anos após a publicação de $O$ País do carnaval, obra de estreia perpassada de manifesto ceticismo. Momento em que o autor divide seu tempo entre a atividade literária e a militância política, influenciado pela leitura soviética e a literatura social europeia e norte-americana, sob o contexto de radicalização ideológica da década de 1930, o romancista baiano publica seu romance proletário, o qual é bem acolhido pelo público e incita a discussão entre os críticos. Praticamente ignorado até então, o desconhecimento do que precisamente significava tal expressão que ingressava no vocabulário de críticos e escritores leva Jorge Amado, em vez de asseverá-lo, a levantar a interrogação:

\footnotetext{
Tentei contar neste livro, com um mínimo de literatura para um máximo de honestidade, a vida dos trabalhadores das fazendas de cacau do sul da Bahia.

Será um romance proletário? (AMADO, 2001, p. IX).
}

Em entrevista a Alice Raillard, quando era já passada a fase mais politicamente compromissada de sua carreira literária, o romancista diria que não, que não era possível, sob as condições socioeconômicas do contexto em que escrevera Cacau, produzir um romance proletário. "A consciência proletária ainda estava em formação num país que apenas começava a se industrializar e onde não existia, propriamente, uma classe operária; o que havia era o trabalhador manual" (AMADO apud RAILLARD, 1990, p. 55). O escritor desconsidera, assim, a possibilidade do romance proletário num país sem uma classe operária formada, fazendo coro, nesse sentido, com parcela da crítica, que assim entendia os limites da assimilação de um modelo literário estranho à realidade brasileira. Não haveria, nas palavras de Schwarz (1992), um "chão histórico", sobre o qual se poderia construir um gênero que, acompanhando o raciocínio do ficcionista baiano, contradiria as condições contextuais. A militância de esquerda, naquele contexto de radicalização ideológica e de consciência da luta de classes, concentrava-se nos centros urbanos, onde se intensificava, não obstante as marcas da condição retardatária do Brasil, o processo de industrialização. No meio rural enfocado pelo romancista predominariam, segundo o próprio autor, relações de produção semelhantes às de uma sociedade feudal, razão pela qual, em sua autocrítica, "fazer um romance proletário" era "pura pretensão" de sua parte (AMADO, apud RAILLARD, 1990, p. 55).

A leitura de Jorge Amado do quadro socioeconômico nordestino corresponde ao entendimento do Partido Comunista à época de sua militância, uma influência crescente que se refletiria em sua obra. A presença de postulados marxistas em seus romances aproxima-o de escritores do contexto pós-revolucionário russo, com os quais se identifica na literatura operária que quer praticar, mas que não o poderia, de acordo com o escritor, em virtude das condições próprias a uma formação social sob as quais conflitaria a impropriedade de um modelo literário que não teria como se realizar então no Brasil. Daí a situação um tanto quanto contraditória, problemática, de um 
romance que, não obstante procure se inscrever sob as características que constituem o romance proletário, acaba se desdobrando numa construção tensional com as mesmas.

Primeiramente, o proletário retratado no universo ficcional de Cacau não é o trabalhador da fábrica, personagem explorado pela literatura operária em suas condições de trabalho, nos conflitos de classe que o envolvem, nas greves em que toma parte. Seus personagens centrais são os trabalhadores rurais do latifúndio cacaueiro do sul baiano, como anunciado na nota introdutória do livro, na qual, ademais, o romancista declara que, para "um máximo de honestidade" almejado, escreveria com "um mínimo de literatura". A nota, que estigmatizara o autor no decurso de sua produção literária, lido o "mínimo de literatura" como despreocupação formal, expressa na verdade o "projeto ideológico" que norteou o romance de 30, romance caracterizado, segundo Freire, por "seu tom de reportagem social e quase sociológica; a sua capacidade de documentos; as evidências que reuniu de vida esmagada, machucada, deformada por influências de natureza principalmente econômica; os seus transbordamentos políticos" (FREIRE, apud ALMEIDA, 1979, p. 79).

Cacau evidencia esses aspectos, numa tensão entre o documento e a ficção, entre o intento de sondagem e denúncia e a criação, "transbordando", porém, no sentido político aos interesses de propaganda, numa obra em que o escritor militante a entende como "arma", como instrumento de "desalienação". Tais transbordamentos perpassam o romance do início ao fim. Estão no maniqueísmo que rege a definição das personagens, retratadas quase que unilateralmente na exterioridade de sua pertença de classe: os capitalistas sob os traços de ferozes exploradores, como o coronel Manoel, ou "Mané Frajelo", "Mané Miserave Saqueia Tudo" (AMADO, 2001, p. 4), segundo os trabalhadores de sua fazenda, enquanto estes figuram na condição de vítimas daqueles, como Sergipano, o narrador-protagonista que, apesar de explorado na fábrica onde trabalhara, "Não trocaria", ele diz, o seu "trabalho na fiação pelo lugar de patrão" (AMADO, 2001, p. 14). Estão também na idealização do proletário, que ascende a herói, representado sempre sob as duras condições de sua situação de explorado na sociedade de classes, ou, como se diz nas terras do cacau, na condição de "alugado": "- A gente aluga máquina, burro, tudo, mas gente, não", Sergipano comenta. "Alugado... Eu estava reduzido a muito menos que homem..." (AMADO, 2001, p. 23). Há também um forte apelo anticlerical: os padres são vistos e denunciados insistentemente em seus compromissos ideológicos, em seu discurso alienador e corrupção: "Em minha terra os padres dominam tudo", afirma o narrador, em conversa à qual participa uma personagem que acrescenta: "Padre de verdade é o padre Sabino, lá de Itaparica." Segundo ele, "Tem doze filhos." Enfim, o significativo didatismo com que expõe, por meio de situações concretas do quotidiano, o contraste social, a consciência do profundo abismo que separa a humanidade em classes; as comparações são eloquentes, atravessando toda a narrativa: "Ficaram [os trabalhadores] olhando. Como era grande a casa do coronel... E morava tão pouca gente ali. [...] E olharam as suas casas, as casas onde dormiam. Estendiam-se pela estrada. Umas vinte casas de barro, cobertas de palha, alagadas pela chuva." (AMADO, 2001, p. 4). 
Não obstante suas intenções políticas coadunem com a orientação da literatura operária que então influenciava o autor, resultam, no entanto, por conta de suas condições particulares, numa contraditória solução, o intuito documental deformado pelo utilitarismo político. Nesse sentido, as simplificações que opera não atendem senão a demandas extrínsecas, a fins propagandísticos que dispensam um mergulho no intrincado psicológico das personagens para que possam ser vistas na superfície estereotipada da classe a que pertencem. Razão pela qual Sergipano alimenta um espírito de solidariedade apenas aos de sua classe, reservando ódio e desprezo ao seu polo antagônico e aos "representantes" de seus interesses, a exemplo da figura do religioso, conivente para com a manutenção do status quo, que em seus sermões "Ameaçava com o inferno aos maus, que se revoltassem. Oferecia o céu aos que se conformassem." (AMADO, 2001, p. 74). A mesma percepção maniqueísta que o leva a menoscabar Algemiro, capataz do coronel, cuja "ambição resumia-se em enriquecer": "Sentíamos que ele não era dos nossos." (AMADO, 2001, p. 49).

Para Duarte, Cacau é um romance que oscila "entre o documento e a propaganda, entre a amostragem de um caso particular de exploração [...] e a didática elaboração de situações concretas e exemplares de combate e transgressão das normas vigentes." (DUARTE, 1996, p. 55). À descrição de suas condições miseráveis de vida, da exploração de seu trabalho nas fazendas de cacau, dos contrastes de sua classe com a do coronel, seguem-na os propósitos pedagógicos do escritor engajado que quer "falar às massas", e que o faz através das personagens da obra, como quando Sergipano é interpelado por Mária, filha do coronel na fazenda onde trabalha: "- Você não pensa, como Algemiro, em enriquecer?/- Não./- Por quê?/- Porque não sei explorar trabalhadores." (AMADO, 2001, p. 94).

Tanto quanto ao interlocutor, as palavras do protagonista se dirigem também ao leitor, manifesto fito propagandístico que frequentemente conflita com o empenho documental, expresso em seus intentos pedagógicos, assim como no esquematismo com que procura desnudar a sociedade capitalista, ou no viés comunista que se traduz no ideal de transformação. Utopia que Jorge Amado cuidou em exprimir no romance de modo um tanto vago, suas personagens mais intuindo do que de fato "conscientes" de sua condição de classe: "Um dia, um dia...", Roberto diz, em frente ao sobrado do coronel Manoel, em conversa com Sergipano, manifestando primeiramente seu ódio e, depois, uma indefinida esperança, "Esse dia não deve tardar..." (AMADO, 2001, p. 21). Ponto capital, aliás, do projeto ideológico da produção literária amadiana em sua primeira fase, a qual seguiu uma trajetória ascendente de envolvimento com os compromissos do campo político, em Cacau, primeiro romance dessa trajetória, a consciência de classe paira de modo vago no decurso de todo o texto; Sergipano tateia, num movimento progressivo em que sua condição proletária se Ihe evidencia gradualmente, até o desfecho em que rejeita o amor de Mária, impossível por conta do abismo que separa suas classes: "O amor pela minha classe, pelos trabalhadores e operários, amor humano e grande, mataria o amor mesquinho pela filha do patrão." (AMADO, 2001, p. 130).

Condensados em seu desenlace, a idealização do trabalhador, o maniqueísmo, a propaganda são aspectos que perpassam todo o texto, mas que expõem, por outro 
lado, as contradições sob as quais se operou nessa investida de Jorge Amado sujeita às condições específicas em que produziu seu romance proletário dos trabalhadores do cacau. Não obstante preocupado com o interesse documental que norteou o projeto estético-ideológico do chamado romance de 30, o romancista baiano, porém, escreve sob o influxo de um engajamento político que envolve e reverbera em sua obra, comprometendo-a de modo a frustrar o intento de verossimilhança segundo o qual pretende se constituir. Em choque numa obra em que sobressai sua dimensão utilitária, tal intento cede ao interesse que a coloca a serviço dos trabalhadores, impregnando-a com ideias que então constituíam o horizonte político de sua militância.

É da tensão, portanto, entre a inclinação realista dirigida à denúncia social e os propósitos políticos que transbordam a fiç̧ão, que derivam as aludidas contradições, desdobrando-se numa narrativa com feições particulares dentro dos termos - vagos, conflitantes - do que se estabeleceu classificar como romance proletário. É verdade que o deslocamento de um modelo a fim de coaduná-lo às condições contextuais operado por Jorge Amado também o levou, com efeito, a essas contradições. À realidade dissonante do meio sócio histórico explorado no universo ficcional de Cacau - o Nordeste brasileiro, com seus coronéis e o trabalhador rural explorado numa condição quase "servil" - não poderia corresponder, nessa perspectiva, o romance proletário, razão pela qual, talvez, o escritor o tenha reorientado, em seus trabalhos seguintes, no sentido de explorar no meio urbano o operário e suas formas de resistência. De qualquer forma, entre os críticos e os escritores da época preponderava uma noção bastante imprecisa acerca do novo gênero, e embora, nesse sentido, Cacau possa se inscrever ou não como expressão imprópria do romance proletário no Brasil, as contradições que o perpassam resultam, de fato, de um projeto ideológico que em Jorge Amado assumiu a forma radical de uma concepção da literatura como "arma" a serviço dos interesses dos trabalhadores e da revolução.

\section{Referências}

ALMEIDA, Alfredo Wagner Berno de. Jorge Amado: política e literatura: um estudo sobre a trajetória intelectual de Jorge Amado. Rio de Janeiro: Campus, 1979.

AMADO, Jorge. Cacau. 53. ed. Rio de Janeiro: Record, 2001.

BUENO, Luís. Uma história do romance de 30. São Paulo: Editora da Universidade de São Paulo; Campinas: Editora da Unicamp, 2006.

CANDIDO, Antonio. Literatura e sociedade: estudos de teoria e história literária. 7. ed. São Paulo: Ed. Nacional, 1985.

DACANAL, José Hildebrando. O Romance de 30. 3. ed. Porto Alegre: Novo Século, 2001.

DUARTE, Eduardo de Assis. Jorge Amado: romance em tempo de utopia. Rio de Janeiro: Record; Natal: UFRN, 1996.

LAFETÁ, João Luiz. 1930: a crítica e o Modernismo. São Paulo: Duas Cidades, 2000. 
RAILLARD, Alice. Conversando Com Jorge Amado. Tradução de DYMETMAN, Annie. Rio de Janeiro: Record, 1990.

SCHWARZ, Roberto. "As ideias fora do lugar". In: Ao vencedor as batatas. São Paulo: Duas Cidades, 1992.

\section{Title}

Under the demands of time: the political horizon in Jorge Amado's literary project

\section{Abstract}

The publication of Jorge Amado's Cacau, in 1933, embedded in a context of ideological struggles, raised the discussion among critics and writers about the socalled "proletarian novel", which had seldom been mentioned in Brazil. Despite the following passionate debates, the genre still lacked a proper meaning as it was understood according to different - and often conflicting - notions. This article readdresses the questions, now under Roberto Schwarz's perspective on Brazilian intellectual experience, marked by the import and displacement of foreign ideas whose impropriety is expressed in the contradictions presents in the dissonant context of their assimilation. Taking on the debate about the publication of Cacau, this article aims at relating it to Amado's ideological project expressed in his literary career in order to understand the novel in the displacements operated by the writer so as to adjust the book to the contextual conditions under which it was written.

\section{Keywords}

Proletarian novel. Jorge Amado. Cacau.

Recebido em 26/09/2012. Aprovado em 20/10/2012. 